DOI: 10.20472/IAC.2019.051.040

\author{
ULRICH GABRIEL STRUNZ \\ UCAM Universidad Católica San Antonio de Murcia, Germany

\section{OVERCOMING ROUTINE: A 21ST CENTURY SKILL FOR A 21ST CENTURY ECONOMY}

\begin{abstract}
:
Economic decision making is governed by complex problems. During complex problem solving, not all relevant information will be available to the decision-maker at first sight. Knowledge is derived from generally incomplete information and is accompanied by uncertainty. This can lead to falsely confirming one's understanding of the true rules governing a complex problem. Bad choices can then lead to good outcomes, further strengthening a wrong mental model, eventually leading to inefficient strategies. The decision-maker can then either rely on old strategies or begin to gather new information, perform counterintuitive actions to override former rule knowledge and thus engage in non-routine problem solving. Curiosity might favor such behavior, as it is the recognition, pursuit and desire to explore uncertain and ambiguous events. To analyze the decision patterns of participants who are more successful in overcoming routine and to find possible correlations with curiosity, two hundred sixty-two US-American Mturks completed both a curiosity questionnaire and an experiment in the form of a cognitive puzzle game. High values in "Joyous Exploration" were not associated with larger numbers of experimental decisions, while about $10 \%$ of the participants who succeeded in obtaining true rule knowledge performed less experimental decisions, reported higher response times, but solved the experiment more efficiently. As shown, overcoming routine is an essential "21st Century skill“ in economic decision making that requires learning from unexpected feedback, benefits from reflection time and is shown to be a serious mental challenge.
\end{abstract}

\title{
Keywords:
}

complex problem solving, dynamic decision making, response time, decision bias, mental model, cognitive reflection, overcoming routine, non-routine task, curiosity, emotion

JEL Classification: D81, D83, D91 